\title{
Health inequities faced by Ethiopian migrant domestic workers in Lebanon
}

\section{Bina Fernandez}

(Pre-publication version of paper published in Health and Place:

Fernandez, B. 2018. "Health inequities in an 'other' place: the healthcare needs and strategies of Ethiopian migrant workers in Lebanon" Health and Place 50 :154-161.)

\section{Introduction}

Health-seeking behaviour and inequitable access to healthcare are well-recognised as being differentiated by the socio-economic status of patients such as race, class and gender (Ensor and Cooper 2004; Hall 2003; Street et.al 2007, Braveman and Gruskin 2003). Such inequities in access to healthcare are often intensified for international migrants as a socioeconomic group with less privileged status than citizens (Thomas and Gideon 2013). Further, migrants with precarious, temporary or irregular status are more vulnerable and marginalised than regular migrants, as they are often unable to avail of formal healthcare services through either the state or the market at destinations (Castaneda 2009; Cuadra 2010; Villarroel and Artazcoz 2012; Cimas et al 2016; Boso and Vancea 2016). Inequities in health faced by migrants may be due to entitlement failures contingent on their migrant status (temporary contract migrants, or migrants with undocumented or irregular status) and/or due to access barriers of gender, class, race and ethnicity, or language.

This paper seeks to deepen our understanding of how marginalised migrants meet their healthcare needs through an analysis of Ethiopian migrant domestic workers' (MDWs) access to healthcare in Lebanon. The healthcare needs of MDWs in Lebanon are mediated by employers and insurance companies, who are legally liable for, but often refuse to bear, the cost of medical treatment for illness or injury. On the contrary, employers may sometimes be responsible for uncaring and even abusive practices (Human Rights Watch. 2010; Jureidini 2002, 2011). Given this context, the key questions examined here are: How do Ethiopian MDWs meet their healthcare needs when they face minor and major illnesses, pregnancy, accidents and 
emergencies? How does migrant status shape the experience of accessing healthcare? In what ways do Lebanese policies support or obstruct access to healthcare?

The paper provides responses to these questions by first, situating them within a conceptual framework on migrant health inequities and by outlining the research design and methods of this project. Next, the paper discusses the contours of the migration and healthcare regimes within which Ethiopian MDWs in Lebanon are located. This is followed by a set of narrative vignettes from interviews and ethnographic observation to describe the experiences of MDWs within four categories of healthcare needs: minor illness, pregnancy, major illness and emergencies. The concluding section analyses the inequities faced by Ethiopian MDWs along two the two dimensions of systemic inequities and inter-personal discrimination, and offers an analysis of the access to healthcare by MDWs differentiated by migrant status.

\section{Migrant health inequities: conceptual framework and research design}

The multiple and often interchangeable usage of the terms 'health inequalities', 'health inequities' 'health differences' and 'health disparities' indicate on the one hand, scholarly agreement that group based variations exist in health achievements and access to healthcare that are not attributable to biological differences; on the other hand, the first two terms also indicate a further dimension of an ethico-political judgement that such variations in health are socially produced, and therefore can and should be amended (Isaac 2012). One of the earliest definitions of the terms health inequality and inequity by Margaret Whitehead is: "Health inequalities are differences in health that are 'avoidable,' 'unjust,' and 'unfair.' Equity in health means that all persons have fair opportunities to attain their full health potential, to the extent possible" (Whitehead 1991). Research on health inequalities has produced a large body of evidence of differences in morbidity, mortality, and access to healthcare among population groups defined by factors such as socioeconomic status (SES), gender, race or ethnicity, much of it focused on the health impacts of race in the U.S and Europe (Kronenfield 2012, La Veist 2012, Bhopal 2007). Notably, Paradies' systematic review of 138 studies on racism and health found considerable variation in the conceptualisation of racism, and that 'only about half the studies recognised systemic racism (i.e. racism occurring through societal organisations, institutions, 
laws, policies, practices etc.) as well as interpersonal racism (i.e. racist interactions between people)" (Paradies 2012: 110). However, this literature on health inequalities has evolved largely in parallel to the literature on migration and health, with little systematic consideration of the areas of overlap and divergence in the usage of the terms race, ethnicity, migrant and immigrant as they pertain to inequities in health (Malmusi et al 2013). While migrants are often subjected to the forms of discrimination experienced by native born racial and ethnic minorities, they are additionally subject to exclusions contingent on their migrant status, with implications for their health.

The complex relationship between migration and health has largely focused on migrants to Europe, the U.S, Canada and Australia. Such studies have often found evidence of the "healthy migrant' effect in which migrants are recruited, and self-select, from amongst those who are healthiest, and who initially report better health compared to the native population, an advantage that is, however, observed to deteriorate over time, producing the 'exhausted migrant' effect where migrants may experience an excessive burden of morbidity, disability and mortality (Bollini and Siem 1992). In identifying what happens in between these two temporal points, conceptually, there are four broad categories of factors that can be considered to influence migrant health, briefly outlined below.

First, migrants' status (documented/undocumented, forced/voluntary, skilled/unskilled) is increasingly a critical determinant of their access to healthcare at destinations. Notwithstanding the recognition of health as a fundamental human right in international human rights law, the absence of enforcement mechanisms makes it difficult to make claims, and particularly for migrants, such rights are increasingly contingent on their status as citizens or legitimate, documented residents of the host state (Willman 2013). Unfortunately, the portability of migrants' rights to healthcare and other social security entitlements is accessible only to a privileged $23 \%$ of all migrants worldwide, who are generally documented, skilled migrants voluntarily moving between countries of the global North (Avato et.al 2010). Second, the nature of the host society's policies of assimilation, integration or pluralism in providing linguistic and culturally competent health services. For e.g., Giannoni et.al (2016) found that weak or absent migrant integration policies negatively influence migrant health; while a systematic review found 
pregnant migrant women at risk for worse outcomes in countries with weak migrant integration policies (Bollini et.al 2009). Third, the characteristics of the migrant such as gender, age, education, class, alongside socio-cultural factors such as ethnicity, religion, rural or urban origin, influence ideas and practices around health, illness, diet, and lifestyle. Fourth, work related health problems, particularly for low-wage migrants who tend to be concentrated in '3-D' (dirty, dangerous and difficult) jobs - including occupational hazards due to poor working conditions and lack of compliance with safety requirements, issues of access to care and compensation for work related injuries, the risk of poor mental health due to chronic stress, discrimination and exploitation.

Each of these four sets of factors influences the access to healthcare by migrant domestic workers, as a disadvantaged and vulnerable group of international migrants who "find themselves in a more vulnerable position, often exacerbated by their possession of temporary permits or irregular legal status, by lack of language skills, or knowledge of rights" (Carrasco 2016 :228). Research on MDWs health needs and access to healthcare has confirmed observations of discrimination and other barriers when they seek healthcare (Bedri et.al 2015, Tshabalala, and Van der Heever 2015, Shlala and Jayaweera 2016), high-levels of mental stress (Van der Ham et.al 2014), but also, that support from co-ethnic migrant, religious and other social networks plays a crucial mitigating and supportive role (Alexandre et.al 2016, Carrasco 2008, Menjivar 2001).

Drawing on the concepts of systemic health inequities and inter-personal discrimination (Paradies 2012), this paper provides evidence for inequitable access to healthcare experienced by Ethiopian women in Lebanon. I identify the specific forms of exclusion they experience and develop a matrix for analysis of access to healthcare differentiated by migrant status. Through this analysis, the paper contributes to the understanding of health inequities faced by migrants in a middle-income country outside the global North, where there are no pathways to long-term settlement and citizenship, and there is no entitlement to state provided health services, rather, the reliance is on the market based provision of healthcare through private health insurance that employers are legally bound to purchase for the MDWs they employ.

The paper draws on empirical material from a qualitative research project that investigates the care needs and practices of Ethiopian migrants. I undertook field research in 
Lebanon between July - September 2016, and conducted semi-structured interviews with 35 MDWs and 17 key informants (including representatives of NGOs, government officials, doctors and health professionals. Contacts from previous research with Ethiopian MDWs in Lebanon in 2010 formed the initial starting point for recruitment of MDW interviewees, through a snowball sample. My access to participants was greatly enhanced due to the active support and collaboration of members of Messawet, an unregistered ${ }^{1}$ Ethiopian organisation of MDWs. Messawet was formed in 2014 by a group of MDWs (one of whom I had met during my field work in 2010) as a mutual support group for MDWs. I followed an embedded ethnographic research strategy, in which I accompanied the leaders of Messawet in their activities - their meetings, visits to hospitals and detention centres/prisons, visits to church, shared meals and even a picnic. These experiences allowed me to develop a fuller understanding of the lives of Ethiopian MDWs, beyond the parameters of interviews I conducted. The selection of interviewees was purposive, to ensure that different types of care needs, migrant status age, ethnicity and religion were covered. Semi-structured, qualitative interviews with MDWs were conducted with the assistance of an interpreter (though I speak and understand basic Amharic). The average duration of interviews was 1 hour, though a few were longer or shorter. Interviews inquired into the women's migration trajectories, employment, and their healthcare needs, practices and experiences. The present paper presents narrative vignettes from in-depth interviews with Ethiopian MDWs in Lebanon. Although the narratives selected are not intended to be representative, the observations on healthcare needs and access are analyzed in triangulation with observations from key informant interviews and the existing academic and grey literature.

\section{Migration and healthcare regimes affecting Ethiopian MDWs in Lebanon}

The use of the term 'migration regime' in this paper follows Williams and Gavanas' (2016) formulation of it as the set of immigration policies that govern the entry, exit, and settlement of migrants and their dependents at a destination country and the attendant rights they are entitled

\footnotetext{
${ }^{1}$ Migrant workers in Lebanon are not allowed to register organisations, unions or associations.
} 
to. Additionally, I include within this term the unwritten cultural norms and practices that mediate migrant status and access to these rights and entitlements.

The 'healthcare regime' for migrants is contingent on the relevant migration regime, but is also shaped by the general framework of healthcare provisioning within a country. In this paper, I take 'healthcare regime' to indicate the organisation of the healthcare system in a country at the levels of: the institutional structures (hospitals, clinics), the services and attitudes of service providers (type and quality of care) and the funding (public, private, non-governmental or combination). The next two sub-sections outline the migration regime and the healthcare regime specific to MDWs in Lebanon.

\subsection{Migration regime: Ethiopian MDWs in Lebanon}

Ethiopian women have been working in Lebanon as MDWs since the 1980s. Lebanon was the primary destination in the Middle East until the Ethiopian government officially banned migration to the country in 2008. Notwithstanding the ban, women continued to migrate to Lebanon, and by 2015, according to data from the Lebanese Ministry of Labour website, there were 73,098 Ethiopian women who constitute $47 \%$ of the 154,757 documented MDWs in Lebanon. Estimates suggest that there are up to 350,000 undocumented MDWs in Lebanon (Shoufi, 2015), of whom a large number are Ethiopian. Most undocumented MDWs have become irregular because they did not renew their iqama (residence) permits under the prevalent Kafala (sponsorship) system (Pande 2013). Some 'freelance' migrant workers make arrangements to 'buy' their iqama from the kafil (sponsor, a Lebanese citizen who should legally also be the employer, but in the case of freelancers, usually is not) so as to maintain a regular status in Lebanon. Freelancers pay highly inflated prices (double or three times the regular cost) to 'buy' their documents, and are technically still considered to be violating the terms of their sponsorship, as they are supposed to work for their sponsor (Beyene, 2005). MDWs who do not manage (or are unaware of how) to maintain a link to a sponsor become 'irregular' or undocumented from the moment they leave the employment of their original sponsor and are immediately at risk of being imprisoned and deported by the General Directorate of General Security (GDGS - the administrative body that controls immigration in Lebanon). 
Officially, according to the terms of the employment contract signed by MDWs, they are not allowed to marry, become pregnant or have children while in Lebanon, yet there is a sizeable population of women migrants with children. According to an interview with a representative of Insan Association, an estimated $5 \%$ of the MDW population have children in Lebanon, the numbers could be around 15,000 . The majority of mothers with children in Lebanon have irregular migrant status, which may have pre-dated their pregnancy, or in some cases, been propelled by it. The Lebanese government restrictions on MDWs rights to legally marry and have children has the unintended counter-effect of propelling these women and their children into irregular status and precarious single motherhood.

Unlike MDWs from countries like Sri Lanka, Bangladesh and the Philippines who tend to migrate after marriage, as I have discussed elsewhere, the majority of Ethiopian MDWs are young, unmarried women in the reproductive and sexually active age group. Consequently, they are highly likely to enter into intimate relationships while in Lebanon, often with migrant men from Sudan and Syria, and sometimes with Lebanese men (Author 2014). Although MDWs are not allowed to register a civil marriage, many Ethiopian women have entered into religious marriage (usually officiated by an Islamic Sheikh), and have had children from these relationships.

\section{2 'Laughing insurance': the migrant healthcare regime in Lebanon}

Lebanon's healthcare regime has been described as 'fragmented and pluralistic' (Institute of Health Management and Social Protection 2012: 29). Following the collapse of the public health sector during the Civil War that ended in 1990, reconstruction and reforms focussed on improved quality of services in the public sector, at both the primary and tertiary levels, and increased increased utilization, particularly among the poor. Slow progress is reflected in the reduction of out-of-pocket expenditure on health from $60 \%$ in 1998 to $44 \%$ by 2012 (ibid: 30).

Notwithstanding the reforms, the healthcare system in Lebanon is still highly inequitable. Using data from the Multipurpose Household Survey in Lebanon (2004-5), Salti et.al (2010) find the lowest quintile of the Lebanese population have lower rates of insurance coverage, and less ability to pay out-of-pocket for healthcare, and yet incur healthcare expenditures more often than the wealthy. Thus, impoverishing health payments are likelier among groups who are 
disadvantaged in terms of income, geography, ethnicity and gender and is associated with lower access to coverage from both private and public insurance. Health insurance plans may be statefunded, such as the National Social Security Fund (NSSF), the Civil Servants' Cooperatives, municipal government plans, and plans of the security and armed forces; or private health insurance plans for the employed, the self-employed and the syndicated (those belonging to professional associations). Less than half of the Lebanese population is covered by any form of health insurance, this drops down to $18 \%$ when the poorest quintile is considered (Salti et.al 2010). Evidence of inequitable access to healthcare and consequent disadvantaged health outcomes has been documented in studies which show inequitable access to healthcare experienced by minority ethnic communities such as the Bedouin (Chatty et. Al 2013, Mansour 2011) and the elderly from Palestinian communities (Sibai et al 2017) in Lebanon. The arrival since 2011 of 1.5 million Syrian refugees in Lebanon has put an additional strain on the already stretched resources of the Ministry of Health and Syrians face extremely harsh conditions of access to health care (Yasmine and Roughalian 2016). It is within the parameters of this inequitable health system which is already skewed against poorer segments of the Lebanese population that we can situate the particular inequalities of the MDW healthcare regime.

Lebanon requires that all MDWs undergo pre-departure health checks as a condition of immigration clearance, to screen for pregnancy and communicable diseases like HIV, tuberculosis (TB), and hepatitis. Upon arrival in Lebanon, the Unified Contract for Migrant Domestic Workers (Decree No. 19/1 dated 31/12/2009) stipulates that all employers must purchase private health insurance for the MDWs they employ. In addition to being a contractual obligation, providing proof of health insurance has become a prerequisite for issuance and renewal of the MDW's annual work permit through the Ministry of Labour. The terms of the health insurance for MDWs are provided in the ninth clause of the Unified Contract as a standard minimum cover for MDWs, which specifies insurance cover for repatriation of the body of a deceased MDW, payments upon permanent or temporary injury from accidents, hospitalization charges after accidents and illness, and an annual health check-up. However, there are significant exceptions to the coverage - all outpatient needs are typically excluded, as is dental care, sexually transmitted diseases, mental illness, abortion, delivery, and injury or death of the MDW due to self-inflicted harm. 
In response to my question about the health insurance policy for MDWs in Lebanon, one of the leaders of Messawet ironically commented: "This is Laughing Insurance", by which she meant that the only thing the insurance guarantees is a (sarcastic) laugh. Even when health insurance is purchased by employers for MDWs working on regular contracts, they often do not benefit from it for the following reasons.

First, although the insurance coverage conditions are standard, the price is variable, and some insurance companies charge as low as 50USD for annual cover. These cheap policies offer token or sometimes even fraudulent cover, designed to only meet the paperwork requirements of the annual renewal of the work permit. Second, several companies provide restricted policies that limit cover to services provided by specific hospitals, which may not be accessible for MDWs, particularly those who live in more remote areas of Lebanon. Third, employers often refuse to allow MDWs access to healthcare services. In part this may be because they fear that if for some reason the insurance cover fails, they would become liable for medical expenses. But it is also because private health insurance cover amongst Lebanese citizens is not widespread, and there may be a lack of awareness on how to make claims. Finally, irregular or undocumented MDWs automatically do not have health insurance coverage and are therefore not guaranteed access, particularly to hospital-based services.

\section{Healthcare needs of MDWs in Lebanon}

Ethiopian MDWs experience the full range of healthcare needs while in Lebanon, which can be categorised into four types of situations: minor illnesses requiring only out-patient care; pregnancies, serious illnesses (such as cancer, tuberculosis or heart problems) and emergencies (due to accidents, assaults or suicide attempts). Each situation is discussed in turn below.

\subsection{Minor illnesses}

The first line of action when MDWs have minor illnesses is to try home remedies they are familiar with, or suggested by friends and family, very often via whatsapp. If this fails, or even concurrently, Ethiopian women frequently seek to treat their illnesses with prayer and 'tsebel' or 'holy water', i.e. water blessed by the Ethiopian Orthodox church. Women working on contract usually also seek help for minor health problems from their employers, and receive varied 
responses. Some employers ignore the request, telling the MDW to pay for treatment herself, as minor illnesses are usually not covered by insurance policies. Some employers give the MDW over-the-counter medicines. As a participant in an FGD narrated:

"I was sick...it was back pain... The madam didn't take me to hospital, rather she used to give me medication and that medication relieved the pain for some time but didn't cure me. Since I really wanted to be cured I used to call my mum in Ethiopia and ask her about the solution. So she used to tell me some advice, like to apply Vicks and tie it to feel better. So I used to apply such things to feel better and work. (Participant 4, FGD 1, Hamra, Beirut, Lebanon)

A few employers do take the MDW to the doctor, and pay for medical treatment either through out-of-pocket expenditure or through insurance, as recounted by an FGD participant:

"She [the employer] took me to the American University hospital and got me treated. Then my ear recovered and I was well. Later, again water entered in this ear and that too she got treated using insurance... She was a rich woman. She paid cash of 1,200 dollars and the insurance returned the money to her" (Participant 5, FGD 3, Daura, Lebanon).

The wealth, status, and even simply the presence of the employer in negotiating the hospital can be an important determinant of the kind of treatment the MDW receives from hospital staff and other patients, as this participant recounts:

"Once I went to the doctor for I got ill in my teeth... when the patients there who are citizens of Lebanon see you, their attitude is why should foreigners get treatment where we get treatment? The treatment the doctors give them and us is very different. The next time I went with my madam. Then the doctor began to treat me better than the treatment he had given me before - I was treated with her status." (Participant 5, FGD 4, Jal El Dib, Lebanon).

This kind of insulation from differential treatment is not available to MDWs who are freelancers or have irregular status and who don't have a sponsor/employer to accompany them, even though they may have the funds to cover the doctor's consultation fees. If they cannot afford the fees, these women use pharmacists as proxy doctors, by asking them to recommend medicines for their ailments. In some neighbourhoods with high migrant populations, primary healthcare clinics operated by NGOs offer low cost services that are availed of particularly by freelance and undocumented MDWs. 


\subsection{Pregnancy}

Since pregnancy is explicitly prohibited by the terms of the MDW contract in Lebanon, MDWs are invariably propelled into precarious irregular status once they become pregnant (Author 2017), and consequently become "undeserving" of healthcare (Constable 2014, Dos Santos 2015). In Lebanon, their irregular status can severely constrain their access to healthcare while pregnant, often making it contingent on the migrant status of the father. Migrant women who are pregnant are particularly vulnerable: existing studies point to a higher health risk profile, poor communication between women and caregivers, a lower rate of obstetrical interventions, a higher incidence of stillbirth and early neonatal death, an increased risk of maternal death, and a higher incidence of postpartum depression (Almeida et. al 2013, Bedri et al. 2015). The next narrative vignette illustrates some of the difficulties facing pregnant MDWs in Lebanon.

\section{'We paid all this money, so why do they treat me like that?': Mulu}

Mulu is a thirty-year old Ethiopian woman who has been in Lebanon for 13 years, and has been irregular for most of this time. She is married (under Islamic law) to a Sudanese migrant in Lebanon, and is the mother of a three-year old son. While she was pregnant, she went for prenatal check-ups every 2 months. Since her husband had his papers, she was accepted for delivery at the hospital, but her experience while giving birth was difficult:

"It was really challenging. I was in labour for two full days. They came - the doctors, the interns, the nurses - they came and came repeatedly, but they didn't treat me.

I was also concerned about my baby - when you call the nurses, they don't come in time to assist you. My breast also didn't have milk at that time, so when he cried repeatedly and I asked for the nurse's help, she told me that he was hungry and the wound of circumcision was making him cry and needed to be cleaned. S,o after they took him out to treat and feed him, they didn't even stay for five minutes. I never want to give birth again! I even told the doctor - we paid all this money [USD1500], so why do they treat me like that?"

While Mulu's experience in the hospital was challenging, other women narrated experiences of even greater difficulties, as they did not have iqamas, they were denied admission to the hospital, and were forced to deliver their babies at home, in some cases even without the support of husband or friends. The often-difficult experiences of pregnant MDWs in accessing 
reproductive health care resonates with the experiences of Bedouin women (Mansour 2011) and Syrian refugee women (Yasmine and Moughalian 2016) in Lebanon, who also face lack of access to emergency obstetric care, limited access to contraception, forced caesarean sections, and high cost of healthcare services. However, both these groups of women are in a relatively advantaged position compared to MDWs, as their pregnancy is not considered illegitimate, and Syrian women are supported by the UNHCR for up to $75 \%$ of their hospital bills.

\subsection{Serious illness}

When MDWs have serious and chronic illnesses, their admission to in-patient care in hospitals is mediated by several factors: first, if they are on contract, it is contingent on their employer's willingness to acknowledge the illness her to the hospital. Second, the level of insurance coverage and the employer's financial capacity will determine what treatments she can obtain. Freelancer women who have their iqama can admit themselves to hospital, but here their financial capacity to pay for hospital services becomes relevant. Third, women who have irregular status will often find it difficult to get admitted without an iqama, and a strategy some women mentioned was to present the iqama of another person, which was accepted by some hospitals.

Once in hospital, some women reported receiving professional treatment and quality care from hospital staff and had no complaints, but several women I met were confronted by the prejudicial attitudes of doctors and hospital staff who treated them as 'less deserving' patients. In part, this is because the hospital staff are concerned that the MDW will be unable to pay the hospital bills (especially if the employer is not involved), but in part, the women believed staff behaviour was driven by racist attitudes towards Ethiopian MDWs. MDW responses to such differential treatment is often of understandable anger, especially if they are paying for the services, as in Mulu's experience. But one of the Messawet members said she was wary of expressing anger to hospital staff, as she was afraid they might then turn around and vindictively treat the patient even worse.

MDWs on regular contracts have, in some cases, been able to access insurance coverage for serious illnesses. Frequently though, even if MDWs with serious conditions are able to access 
health insurance, it may still be insufficient for their healthcare needs. As a doctor actively involved with MDW healthcare at a private hospital in Jbeil noted, the low level of insurance coverage for MDWs has limitations:

"The problem is when they are admitted, their insurance is low-level insurance and not does not cover all issues, so we have to pay attention to this. We cannot ask for any exam. And every exam should be even more indicative. If you have to ask for ultrasound for the kidney we have to proceed with urinalysis first, and if urinalysis is positive, only then will the insurance accept [a request for ultrasound]" (Interview, Doctor N., Maritime hospital, Jbeil).

While a few employers do pay for treatment of serious illness, even out-of-pocket, many employers seek to transfer the costs to the MDW, and in some cases will also try to terminate the contract, as Ayantu below describes when she was hospitalised for liver problems:

"The first time when I was in the madam's house, I stayed twenty days in hospital, then after I left hospital she said 'If I don't fire you, I can't bring another worker'. At that time, I couldn't move. She wanted to put me on a flight back. Yet the doctor said she couldn't for minimum of one year. My lqama was renewed at that time. I stayed with the employment agent. There I faced a lot of problems. The employment agent wanted to get rid of me as though I was garbage. But I stayed there for three months. Then I decided to run away and live anyway, taking the risk of going to prison" (Participant 7, FGD 4, Jal El Dib, Lebanon).

Like pregnancy then, serious illness can also propel women into irregular status, as in the case of the woman above, and generate an overall downward trajectory in their well-being and vulnerability.

Tuberculosis (TB) is a special case of a communicable serious illness in which treatment costs are highly subsidised by the Ministry of Health in Lebanon. Upon diagnosis, both Lebanese citizens and migrant workers are referred to a TB sanatorium attached to an Armenian hospital in Azounieh - though migrant workers are accommodated separately. In a focus group discussion with a small group of the MDW inmates (a mixed group of Ethiopian and Filipina women) I learnt that at Azounieh, in-patient treatment is provided at the rate of USD300 per patient, and some employers pay for this, while others leave the MDW to pay for it herself. Further, the women had to pay for their own food and water. According to a doctor I interviewed at Azounieh, about half of those admitted did not have employers who took responsibility for them. 


\subsection{Accidents and Emergencies}

Several of the healthcare professionals I interviewed said that in the case of emergencies,

MDWs received the same lifesaving medical care as would be given to any Lebanese person. However, one doctor more candidly admitted, that this was not necessarily true in all hospitals:

"We have a procedure called 'urgently needed procedure', [whether it is] for a migrant or not. It's up to the emergency physician to assess the case and to say to the director [of the hospital], I need this. This is an urgently needed procedure and they are obliged to accept. So it's a good execution of patient rights. But it's not the same in Lebanon. You have 10 or 15 percent of hospitals in Lebanon working correctly with emergency cases. Otherwise it depends on the case and on the migrant worker. If the migrant worker is working in a home for very well known people, it's a question of contacts... if you are working for a general in the army and, you know..." (Interview, Doctor N., Maritime hospital, Jbeil).

The doctor's observation of the importance of the status and contacts (of the employer) in mediating the MDW's access to emergency medical care is borne out by other studies of health inequalities in Lebanon, which note that political factors such as ethnicity, religious affiliation and access to influential officials shape access to health care in Lebanon, particularly for lowerincome and needy individuals (Chatty et al 2013; Chen and Cammett 2012).

Injuries due to accidents are the most common insurance claims made, according to the representatives of two major insurance companies I interviewed. The terms of the standard insurance policy require the employer or the MDW to report to the company within 5 days all the details of an accident. Further, in the event of death, the insurance company has the right to request a death certificate, reason for death and doctor's report before any claim can be processed. As reports on the abuse of MDWs in Lebanon have documented, the abuse and assault of MDWs by their employers is often passed off as an 'accident' (Human Rights Watch 2010, KAFA 2014). Interviews with representatives of NGOs supporting MDWs confirmed that very rarely do such serious assaults or deaths become 'medico-legal' cases, as within the power asymmetry of the kafala, it is extremely difficult to hold the employers legally accountable for the abuse perpetrated on MDWs. However, as the narrative vignette below shows, the impact of such accidents can be irrecoverably damaging and life changing. 


\section{Waiting to die: Selam}

Selam is a 28-year old woman who had been in Lebanon only 3 months before she was brought in to Mekassed Hospital with poly trauma injuries, including to her head. She had been brought in by her employer, who claimed that Selam had tried to commit suicide by jumping out of the apartment. However, it was not clear from the nature of the injuries if they were due to a fall (whether accidental or suicidal), or whether this was an assault attempt by the employer. The hospital sought to recover the cost of Selam's medical expenses, but in the initial three months, neither the employer nor the Ethiopian embassy had taken responsibility for her. Reportedly, an embassy official came once and asked about her, but then disappeared. As I have discussed elsewhere (Author 2014), the resources and personnel of the Ethiopian embassies are too limited to enable effective intervention on behalf of its citizens in distress abroad.

After three months, when the members of Messawet found out about her, they went to the hospital and found Selam was in a coma, unresponsive to any stimuli and breathing only with the help of a respirator. The doctor wanted to do a tracheostomy to enable Selam to breathe without the aid of the respirator. The hospital manager said the unpaid bills for three months were 45,000 USD, but the hospital was prepared to accept 1,600 USD just to undertake the operation. Messawet raised the funds for this procedure by collecting contributions from members and well-wishers. Selam adapted to the implant in her neck, but now needed another procedure in her side so that she could be fed directly (since her throat was now open, she could not be fed through her mouth). Again, another 1200USD (negotiated down from 1700USD) was raised by Messawet to pay for this feeding tube. After this procedure, Selam started responding to sound, turning her head when her name was called, though her eyes still had a vacant gaze.

Although the hospital staff were reluctant to make a prognosis, it seemed that she was unlikely to recover full functioning. The two procedures were undertaken primarily to enable her to be transported back to Ethiopia on a stretcher. The hospital wanted to move Selam out, as she is in a separate single room and the cost of the bed and treatment is rising, however, in order to travel, Selam's employer would have to release her passport, or the Embassy would have to take responsibility. The employer refused to release Selam's passport without a guarantee that she 
would not be liable for the unpaid hospital bills, which the hospital manager would not agree to. The Embassy had not taken any action at the time I was there.

Meanwhile, Messawet members contacted Selam's husband and four children, however, the family is very poor and doesn't have the resources or capacity to give her the care she needs. Messawet therefore contacted the Ethiopian NGO Agar which supports returnee MDWs and were trying to arrange for her care there. Here again, the process stalled, ostensibly because Agar did not have an ambulance to transport Selam from the airport in Addis Ababa, however when I interviewed an Agar staff member, he explained that the organisation did not have the capacity to provide the 24 -hour nursing care Selam needed. So, over a year after her injury, Selam was still in the hospital, waiting to die.

\section{Conclusion: systemic inequities and inter-personal discrimination in MDW access to healthcare in Lebanon}

Drawing on the preceding account of the healthcare needs of Ethiopian MDWs in four types of situations and on Paradies' (2012) bi-fold categorisation of systemic health inequities and inter-personal discrimination, I argue that Ethiopian MDWs face both types of inequities in access to healthcare in Lebanon, and discuss each in turn below. The evidence presented in this paper suggests that the MDW experience of systemic inequalities attributable to gender, socioeconomic status and ethnicity are intensified and compounded by specific forms of disadvantage that are a consequence of their migrant status. That is, while the systemic inequities in access to healthcare faced by MDWs is comparable to those faced by low income, minority ethnic Lebanese communities (and particularly the women of these communities) within the highly stratified healthcare system of Lebanon, variations in migrant status produce additional inequalities of access. Further differentiating 'migrant statuses', Table 1 below delineates variations in systemic health inequities for MDWs with three types of migrant status: MDWs on regular contracts, freelancer MDWs, and irregular MDWs. 
Table 1. Inequities in MDWs' access to healthcare in Lebanon

\begin{tabular}{|c|c|c|c|c|c|c|c|}
\hline $\begin{array}{l}\text { Migrant } \\
\text { status }\end{array}$ & $\begin{array}{l}\text { Health risks and } \\
\text { vulnerabilities }\end{array}$ & $\begin{array}{l}\text { Health insurance } \\
\text { coverage }\end{array}$ & $\begin{array}{l}\text { Access to } \\
\text { private } \\
\text { doctors }\end{array}$ & $\begin{array}{l}\text { Access to public } \\
\text { hospitals }\end{array}$ & $\begin{array}{l}\text { Access to private } \\
\text { hospitals }\end{array}$ & $\begin{array}{l}\text { Access to NGO } \\
\text { clinics }\end{array}$ & $\begin{array}{l}\text { Access to co- } \\
\text { ethnic } \\
\text { support } \\
\text { networks }\end{array}$ \\
\hline $\begin{array}{l}\text { Contract } \\
\text { DW }\end{array}$ & $\begin{array}{l}\text { Occupational health } \\
\text { (over work, } \\
\text { accidents) } \\
\text { Poor diet } \\
\text { Abuse by employer }\end{array}$ & $\begin{array}{l}\text { Formal cover, } \\
\text { price and level of } \\
\text { cover varies }\end{array}$ & $\begin{array}{l}\text { Contingent on } \\
\text { employer } \\
\text { permission }\end{array}$ & $\begin{array}{l}\text { Contingent on } \\
\text { insurance cover } \\
\text { and employer } \\
\text { permission }\end{array}$ & $\begin{array}{l}\text { Contingent on } \\
\text { insurance cover and } \\
\text { employer permission }\end{array}$ & $\begin{array}{l}\text { Contingent on } \\
\text { employer } \\
\text { permission and } \\
\text { local availability }\end{array}$ & $\begin{array}{l}\text { Limited or } \\
\text { no access }\end{array}$ \\
\hline $\begin{array}{l}\text { Freelance } \\
\text { DW }\end{array}$ & $\begin{array}{l}\text { Occupational health } \\
\text { (over work, } \\
\text { accidents) } \\
\text { Poor housing } \\
\text { conditions }\end{array}$ & $\begin{array}{l}\text { Formal cover, } \\
\text { price usually the } \\
\text { minimum } \\
\text { required to obtain } \\
\text { a residence } \\
\text { permit }\end{array}$ & $\begin{array}{l}\text { Contingent on } \\
\text { capacity to pay } \\
\text { out of pocket }\end{array}$ & $\begin{array}{l}\text { Contingent on } \\
\text { ability to show } \\
\text { residence permit, } \\
\text { and capacity to pay } \\
\text { out of pocket }\end{array}$ & $\begin{array}{l}\text { Contingent on ability } \\
\text { to show residence } \\
\text { permit, and capacity } \\
\text { to pay out of pocket }\end{array}$ & $\begin{array}{l}\text { Contingent on } \\
\text { ability to pay } \\
\text { and local } \\
\text { availability }\end{array}$ & $\begin{array}{l}\text { Generally } \\
\text { good access }\end{array}$ \\
\hline $\begin{array}{l}\text { DW with } \\
\text { irregular } \\
\text { status }\end{array}$ & $\begin{array}{l}\text { Occupational health } \\
\text { (over work, } \\
\text { accidents) } \\
\text { Poor diet and } \\
\text { housing conditions } \\
\text { Heightened mental } \\
\text { stress due to fear of } \\
\text { detention and } \\
\text { deportation }\end{array}$ & No cover & $\begin{array}{l}\text { Contingent on } \\
\text { capacity to pay } \\
\text { out of pocket }\end{array}$ & $\begin{array}{l}\text { Limited or no } \\
\text { access }\end{array}$ & $\begin{array}{l}\text { Contingent on ability } \\
\text { to show residence } \\
\text { permit of a } \\
\text { guarantor, and } \\
\text { capacity to pay out of } \\
\text { pocket }\end{array}$ & $\begin{array}{l}\text { Contingent on } \\
\text { ability to pay } \\
\text { and local } \\
\text { availability }\end{array}$ & $\begin{array}{l}\text { Generally } \\
\text { good access }\end{array}$ \\
\hline
\end{tabular}


Analysing the variations in access to healthcare by migrant status, this paper finds that access to healthcare by MDWs on a regular contract is highly contingent on their employers, at multiple levels. First, their exposure to health risks include potential for maltreatment (overwork, food and sleep deprivation) and abuse (physical, sexual or emotional) by the employer, which is by now well-documented (Human Rights Watch 2010, KAFA 2010). The employer determines the level of health insurance cover and is essential in making claims on the insurance company. Crucially, the employer will also determine the MDWs access to medical care at all and co-ethnic support networks. Thus, while health insurance provides MDWs on contracts formal entitlements to healthcare, in practice, realizing access to these entitlements has frequently proved difficult for MDWs on contracts.

The migrant status of 'freelancer' often ensures relatively better access to healthcare, as the freelancer lives independent of her employer. A freelancer may generally have better income and consequently better capacity to pay for private healthcare, even if her health insurance coverage is only token. Moreover, she is able to access support from co-ethnic and other migrant social networks.

MDWs with irregular status are the most vulnerable as their lack of the iqama (residence permit) means they often delay seeking timely healthcare due to their fear of being apprehended. They may also be refused access to healthcare services in hospitals, unless they can produce the identification documents (citizen or residence permit) of a guarantor. Further research would be necessary to identify the extent to which MDWs and other migrant workers are refused admission to the heath sector, and the extent to which hospitals vary in regulations and practices of admission, as well as their treatment of MDWs.

We see therefore that at the systemic or institutional level, the healthcare access for MDWs in a middle-income country like Lebanon is weaker than for ethnic minority Lebanese citizens, or for Syrian and Palestinian refugees with a UNHCR mandate. MDW access to healthcare is also relatively disadvantaged compared to the experience of migrants in Europe or North America discussed in the systematic review by Suphanchaimat et.al (2015). Suphanchaimat et.al (2015) found that laws in these countries limiting migrants' right to healthcare were often circumvented by healthcare providers who partially ignored the immigrants' precarious legal 
status to provide them with healthcare; however, in Lebanon this appears less likely to happen. MDW patients are often refused care if they don't have the right documents, or the financial resources. Such exclusion is legitimized within a privatized healthcare system where, as noncitizens, migrant workers are excluded from the limited universal health provisioning that exists for citizens. Such exclusion also perpetuates systemic inequalities at the global level, as while labour is extracted from healthy MDWs in the (middle-income) host country, the negative burden of morbidity and mortality of unhealthy MDWs is exported back to the (low-income) sending country.

Turning to the second type of inequity - inter-personal discrimination, the paper has provided evidence that MDWs do face inter-personal discrimination from hospital staff (doctors and nurses), which is in consonance with Carrasco's (2008) observations of the significance of race as a factor influencing denial of access to healthcare experienced by Peruvian migrant domestic workers in Chile, despite that country's well-developed health system. That said, there is scope for further research to systematically investigate: to what extent is the inter-personal discrimination in access to health care Ethiopian MDWs experience attributable to a less acknowledged but nevertheless deep-seated racism based on skin colour and ethnic difference, and to what extent is it attributable to their migrant status as a non-citizen foreigner? The existence of a racialized hierarchy in the wages and treatment of MDWs in Lebanon (Author 2011) suggests that there may be a concomitant racialized hierarchy of differential access to and treatment in, healthcare amongst MDWs. The experiences of the women in this research indicates that their experience of discrimination may be more intense than that experienced by MDWs of other nationalities, due to their racial identity. Further research would be necessary to identify the extent to which Ethiopian MDW experiences of interpersonal inequities in access to healthcare differs from those of MDWs of other nationalities in Lebanon, other categories of migrant workers, and ethnic minorities in Lebanon. 


\section{References}

Almeida, Lígia Moreira, José Caldas, Diogo Ayres-de-Campos, Dora Salcedo- Barrientos, and Sónia Dias. 2013. Maternal healthcare in migrants: a systematic review. Maternal And Child Health Journal 17 (8):1346-1354. doi: 10.1007/s10995-012-1149-x.

Bedri, Nafisa, Sara Ibrahim Abdelmoneim, Nuha Tambal, and Suzan Adam. 2015. Factors influencing access of women migrant domestic workers to sexual and reproductive health (SRH) services at Khartoum State: the case of Ethiopian migrant domestic workers. The Free Library. Accessed 3 March 2017.

Bollini P, Pampallona S, Wanner P, Kupelnick B. 2009. Pregnancy outcome of migrant women and integration policy: A systematic review of the international literature. Social Science \& Medicine 68: 452-461.

Boso, Àlex, and Mihaela Vancea. 2016. Should irregular migrants have the right to healthcare? Lessons learnt from the Spanish case. Critical Social Policy 36 (2):225-245.

Braveman P and S. Gruskin. 2003. Defining equity in health. Journal of Epidemiology and Community Health 57:254-258.

Carrasco, Lorena Núñez. 2016. Migration, gender and health. In Handbook on gender and health, edited by Jasmine Gideon. Northampton, MA: Edward Elgar Publishing, Inc.

Carrasco, Lorena Núñez. 2008. Living on the Margins: Illness and Healthcare among Peruvian Migrants in Chile. Unpublished PhD thesis. University of Amsterdam.

Castaneda, H. 2009. Illegality as risk factor: survey of unauthorized migrant patients in a Berlin clinic, Social Science and Medicine, Vol. 68, No. 8, pp. 1552-1560.

Chatty, Dawn, Nisrine Mansour and Nasser Yassin. 2013. Bedouin in Lebanon: Social discrimination, political exclusion, and compromised health care. Social Science and Medicine $82: 43-50$.

Constable, Nicole. 2014. Born Out of Place: Migrant Mothers and the Politics of International Labor. California: University of California Press.

Cuadra, C. 2010. Policies on health care for undocumented migrants in EU-27, Country reports Germany, Greece \& Sweden, The Health Care in Nowhereland project.

Dos Santos, Sara Leon Spesny. 2015. Undeserving mothers? Shifting rationalities in the maternal healthcare of undocumented Nicaraguan migrants in Costa Rica. Anthropology \& Medicine 22 (2):191-201.

Ensor T, Cooper S. 2004. Overcoming barriers to health service access: influencing the demand side. Health Policy Planning 19:69-79.

Giannoni, Margherita, Luisa Franzini and Giuliano Masiero. 2016. Migrant integration policies and health inequalities in Europe. BMC Public Health 16:463.

Hall J. A. 2003. Some observations on provider-patient communication research. Patient Education Counselling 50:9-12

Human Rights Watch. 2010. Without Protection: How the Lebanese Justice System Fails Migrant Domestic Workers. New York: Human Rights Watch.

Isaac, Lydia. 2012. Defining Health and Health Care Disparities and Examining Disparities Across the Life Span. In Race, Ethnicity, and Health : A Public Health Reader, edited by Thomas A. LaVeist, John Wiley \& Sons. 
Institute of Health Management and Social Protection. 2012. National Health Statistics Report in Lebanon. Beirut: The Institute of Health Management and Social Protection (IGSPS).

Jureidini, R. 2002. Women migrant domestic workers in Lebanon. International Migration Papers. Geneva: International Labour Office.

Jureidini, Ray. 2011. An Exploratory Study of Psychoanalytic and Social Factors in the Abuse of Migrant Domestic Workers by Female Employers in Lebanon. KAFA (enough) Violence \& Exploitation.

Mansour, Nisrine. 2011. Gender at the Margins: Bedouin Women's Perceptions of Lebanese Health Provision. International Journal of Migration, Health and Social Care, 6(3):42-52.

Menjivar, C. 2001. The ties that heal: Guatemalan immigrant women's networks and medical treatment", International Migration Review 36(2):437-466.

Pande, Amrita. 2013. 'The Paper that You Have in Your Hand is My Freedom': Migrant Domestic Work and the Sponsorship (Kafala) System in Lebanon. International Migration Review $47(2): 414-441$.

Paradies, Y. 2012. A systematic review of empirical research on self-reported racism and health. In Race, Ethnicity, and Health : A Public Health Reader, edited by Thomas A. LaVeist, John Wiley \& Sons.

Salti, Nisreen, Jad Chaaban, and Firas Raad. 2010. Health equity in Lebanon: a microeconomic analysis. International Journal for Equity in Health 9:11-31.

Shlala, Elizabeth and Hiranthi Jayaweera. 2016. The Right to Health: Sri Lankan Migrant Domestic Workers in the GCC. Muslim World Journal of Human Rights 13(1): 75-100.

Shoufi, E. 2015. Examining Lebanon's Demographic Realities. Al Akhbar - English. [online] Available at: http://english.al-akhbar.com/node/23729 [Accessed 13 Aug. 2016].

Sibai, Abla Mehio, Anthony Rizk and Hiam Chemaitelly. 2017. Self-rated health disparities among disadvantaged older adults in ethnically diverse urban neighborhoods in a Middle Eastern country. Ethnicity \& Health, 22:5, 490-509

Street Jr RL, Gordon H, Haidet P. 2007. Physicians' communication and perceptions of patients: Is it how they look, how they talk, or is it just the doctor. Social Science Medicine 65:58698.

Suphanchaimat, Rapeepong, Kanang Kantamaturapoj, Weerasak Putthasri, and Phusit Prakongsai. 2015. Challenges in the provision of healthcare services for migrants: a systematic review through providers' lens. BMC Health Services Research 15:390-390.

Thomas, Felicity. 2010. Transnational health and treatment networks: Meaning, value and place in health seeking amongst southern African migrants in London. Health and Place 16 (2010) 606-612.

Thomas, Felicity and Jasmine Gideon (eds). 2013. Migration, Health and Inequality. Chicago: University of Chicago.

Tshabalala, M.M. \& Van der Heever, H. 2015. Health seeking behaviours of migrant domestic workers in Centurion, South Africa. African Journal for Physical, Health Education, Recreation and Dance, October (Supplement 2:2), 275-286.

Villarroel, Nazmy and Lucia Artazcoz. 2012. Heterogeneous patterns of health status among immigrants in Spain. Health and Place 18: 1282-1291. 
Williams, F. and A. Gavanas. 2007. The Intersection of Childcare Regimes and Migrant Regimes: a three country study. In Helma Lutz (ed) Migration and domestic work : a European perspective on a global theme. Aldershot, England: Ashgate.

Whitehead, M. (1991). The concepts and principles of equity and health. Health Promotion International, 6(3), 217-228.

Yasmine, R and C Moughalian. 2016. Systemic violence against Syrian refugee women and the myth of effective intrapersonal interventions Reproductive Health Matters, 24:27-35. 